\title{
OFFENSIVE AND DEFENSIVE PLAY IN HANDBALL IN A 2-YEAR WORLD CHAMPIONSHIP CYCLE: CHARACTERISTICS AND TENDENCIES
}

\author{
KAROL GRYKO1, SŁAWOMIR BODASIŃSKI², ANNA BODASIŃSKA², JANUSZ ZIELIŃSKI2 \\ IJózef Pitsudski University of Physical Education in Warsaw, Faculty of Physical Education, \\ Department of Athletics and Sport Games, Warsaw, Poland \\ 2Józef Pitsudski University of Physical Education in Warsaw, Faculty of Physical Education and Sport \\ in Biała Podlaska, Department of Sport Games, Biała Podlaska, Poland
}
Mailing address: Karol Gryko, Józef Piłsudski University of Physical Education in Warsaw, Faculty of Physical Education, 34 Marymoncka Street, 00-968 Warsaw, tel.: +48 228340431 int. 577, fax: +48 228651080 , e-mail: k.gryko@awf.edu.pl

\begin{abstract}
Introduction. The analysis of players' performance with respect to technical-tactical actions is becoming a key factor influencing the focus of training programmes and the contents of training units. It also provides important information which can be used to improve players' efficiency during the game. The aim of the current study was to analyse the efficiency of technicaltactical offensive actions in positional attack as well as defensive actions performed by handball players participating in two consecutive World Men's Handball Championships, held in Spain in 2013 and in Qatar in 2015. Material and methods. The material subjected to analysis was data describing the technical-tactical actions performed during the World Championships in Spain in 2013 and in Qatar in 2015. We analysed offensive and defensive actions, including with regard to the continent the teams represented. We performed an analysis of the documents available on the IHF website. The significance of the differences found was verified using analysis of variance (ANOVA and MANOVA). Results. The study found a significantly lower number of offensive actions in positional attack $(-7.5 \%)$ and turnovers $(-26.4 \%)$, higher overall efficiency $(+7.2 \%)$, as well as higher efficiency of $6-\mathrm{m}$ shots $(+9.5 \%)$, wing shots $(+7.3 \%)$, and breakthrough shots $(+11.4 \%)$ at the World Championship in Qatar compared to tournament in Spain. When it comes to defensive actions, there was a significantly higher number of 2-minute suspensions $(+27.5 \%)$, with a simultaneous significant reduction in the number of steals $(-55.7 \%)$ and shots defended $(-13.3 \%)$. Conclusions. During a two-year cycle, there was a change in the concept of playing in positional attack. In 2015, there was a significantly greater number of actions leading to a shot in the region of the opponent's goal area as well as a higher level of activity and more aggressive play on the part of defensive players. In addition, European teams had gained an advantage over teams from other continents in terms of the efficiency of the technical-tactical actions undertaken.
\end{abstract}

Key words: Handball, offensive and defensive actions, game analysis

\section{Introduction}

Handball is a team game where there is direct contact with the opponent. As a team sport, it has a complex structure, which determines the outcome of the game [1, 2]. Most of the actions performed during the game are characterised by high intensity $[3,4]$ and an intricate structure of the movement. Due to its complexity, handball may be examined in its multiple aspects, such as the following: offensive and defensive play, which includes technical-tactical actions; individual actions of the players; the efficiency with which they perform particular elements; the characteristics of the game; physiological, motor, and mental factors; and players' physique [5, 6, 7]. It is thus important that each of these aspects be thoroughly investigated from a theoretical point of view in order to develop adequate methods aimed at enhancing both the sport discipline, in a global sense, and the performance of the players themselves, so that they can have better achievements and perfect their skills.
The analysis of matches played during the most prestigious tournaments and the observation of players' performance with respect to their technical-tactical skills is becoming a major factor influencing the focus of training programmes and the contents of training units $[8,9,10]$. The effective and rigorous analysis of matches can deliver a range of important information that can be used to improve the efficiency of players' performance [11, 12] and make it possible to determine the new techniques and strategies used by the best players and teams [13], which compel other teams to enhance their technical and motor preparation, stimulating the development of the sport discipline as a whole [14, 15]. Handball players are more and more frequently required to have the highest level of motor preparation with respect to their speed, strength, endurance, and coordination abilities; comprehensively trained players are able to perform versatile actions, both in the attack and defence, and make better decisions on the court [16, 17, 18, 19]. 
Thus, there is a need to record the game in an objective way and analyse particular situations (typical and atypical ones), with respect to both external and internal parameters having to do with the efficiency of the entire team as well as individual players [20, 21, 22]. If performed adequately, match analysis can be a source of valuable information concerning the strengths and weaknesses of one's own team and of that of the opponent $[23,24]$.

In modern handball, multi-faceted analyses are carried out with respect to shots, which are a basic technical element that has a large impact on the outcome of the match $[6,11]$ and on the defensive and offensive strategies [16]. The analyses conducted have concerned the efficiency of the performance of shots depending on the area $[25,26]$, the position of the court $[27,28]$, the time period during which the shots are performed, and sequences of actions [11, 24, 29, 30].

Researchers have also investigated the performance of goalkeepers [31, 32], which, especially in high-level competitions, often determines the outcome of the match, and the efficiency of playing in this position has changed considerably over the past few years.

Moreover, research is carried out with the aim of describing actions performed by teams representing different continents. It has been found that European teams have an advantage over other teams when it comes to their performance efficiency (this is clear when one looks at the outcomes of the Olympic Games and World Championships as well as the ranking of the International Handball Federation from the past 12 years) [11].

The main aim of the current study was to analyse the efficiency of the technical-tactical offensive actions in positional attack as well as defensive actions performed by players participating in two consecutive World Men's Handball Championships, in Spain in 2013 and in Qatar in 2015. The analysis additionally included the sector of the court and tactical situations related to performing the shots, the performance of the goalkeeper, and the continents the teams represented.

\section{Material and methods}

The data analysed concerned teams participating in the World Men's Handball Championships in Spain in 2013 and in Qatar in 2015. The data were quantitative (number of actions recorded) and qualitative (efficiency of actions) and regarded the offensive and defensive actions taken by field players and goalkeepers from all the teams participating in the two tournaments $(n=24)$. We analysed all the matches played during the World Championships in Spain $(\mathrm{n}=84)$ and in Qatar $(\mathrm{n}=88)$, exploring selected types of actions performed in the offence and defence as well as goalkeepers' interventions. A comparative analysis was performed depending on the continent the teams represented.

We examined the documents with the official statistics from the World Championships held in 2013 and 2015 accessible from the website of the International Handball Federation (IHF). These included the following: the total number of shots; the number of shots and goals from particular sectors of the court, turnovers, steals, blocked shots, and 2-minute suspensions; the number of interventions made by the goalkeepers and the efficiency of these interventions with respect to shots from particular sectors of the court; and tactical situations related to performing shots.

The following values were used in the analysis: mean values $(\bar{x})$, standard deviations (SD), minimal values (Min), maximal values (Max), and percentage values (\%). One-way ANOVA was used to determine the significance of overall differences related to the structure of the game played by particular teams during the World Championships in Spain and in Qatar (irrespective of the continent represented), whereas multivariate analysis of variance (MANOVA) was used to analyse the differences depending on the continents represented. Statistical significance was set at $\mathrm{p}<0.05$. All the calculations and analyses were made using STATISTICA software (v. 12, StatSoft, USA).

\section{Results}

The analysis of the level of overall differences in offensive actions in positional attack (Tab. 1) revealed a significant decrease in the number of all actions $(-7.5 \%, \mathrm{p}<0.001)$ and turnovers $(-26.4 \%, \mathrm{p}<0.01)$ during the World Championship in Qatar compared to that in Spain. When it comes to the number of attacks with respect to sector of the court and the tactical situations related to performing the shots (Tab. 1), we observed a significantly lower $(\mathrm{p}<0.05)$ number of 9 -m shots $(-9.9 \%)$, breakthrough shots $(-21.6 \%)$, and $9-\mathrm{m}$ goals $(-10.5 \%)$ in the Qatar championship compared to that in Spain. On the other hand, there was a significantly greater $(\mathrm{p}<0.01)$ number of $6-\mathrm{m}$ shots $(+37 \%)$ and $6-\mathrm{m}$ goals $(+56 \%)$ in the former than in the latter. The values for the remaining actions were similar for the two tournaments.

Table 1. Number of offensive actions in positional attack during World Men's Handball Championships in Spain in 2013 and in Qatar in 2015

\begin{tabular}{|l|c|c|c|c|}
\hline \multirow{2}{*}{\multicolumn{1}{|c|}{ Variables }} & \multicolumn{2}{|c|}{$\begin{array}{c}\text { World Championship } \\
\text { in Spain, 2013 }(\mathbf{n = 8 4})\end{array}$} & \multicolumn{2}{c|}{$\begin{array}{c}\text { World Championship } \\
\text { in Qatar, 2015 }(\mathbf{n = 8 8})\end{array}$} \\
\cline { 2 - 5 } & $\bar{x} \pm$ SD & Min-Max & $\bar{x} \pm$ SD & Min-Max \\
\hline All actions & $53.6 \pm 3.1$ & $48.9-61.7$ & $49.6 \pm 3.3^{* * *}$ & $40.8-58.5$ \\
\hline All shots & $41.1 \pm 2.8$ & $34.4-46.2$ & $40.4 \pm 2.3$ & $36.1-44.1$ \\
\hline Efficient shots & $21.9 \pm 3.6$ & $10.1-28.2$ & $23.9 \pm 2.8^{*}$ & $14.2-26.3$ \\
\hline Turnovers & $12.5 \pm 3.6$ & $9.6-27.3$ & $9.2 \pm 2.2^{* *}$ & $6.7-13.4$ \\
\hline 9-m shots & $19.2 \pm 2.8$ & $13.8-24.0$ & $17.3 \pm 3.6^{*}$ & $11.0-26.6$ \\
\hline Efficient 9-m shots & $7.6 \pm 1.5$ & $4.9-9.8$ & $6.8 \pm 1.5^{*}$ & $3.9-9.3$ \\
\hline 6-m shots & $7.3 \pm 1.9$ & $4.3-11.6$ & $10.0 \pm 2.5^{* *}$ & $5.4-16.3$ \\
\hline Efficient 6-m shots & $5.0 \pm 1.4$ & $2.0-7.9$ & $7.8 \pm 1.7^{* *}$ & $3.1-10.3$ \\
\hline 7-m shots & $3.6 \pm 1.0$ & $2.0-6.6$ & $3.9 \pm 0.9$ & $2.9-6.5$ \\
\hline Efficient 7-m shots & $2.6 \pm 0.9$ & $1.1-5.3$ & $2.9 \pm 0.8$ & $1.7-5.3$ \\
\hline Breakthrough shots & $5.1 \pm 1.6$ & $3.1-9.3$ & $4.0 \pm 1.1^{*}$ & $2.3-7.3$ \\
\hline $\begin{array}{l}\text { Efficient breakthrough } \\
\text { shots }\end{array}$ & $3.5 \pm 1.2$ & $1.4-5.8$ & $3.2 \pm 1.1$ & $1.7-6.2$ \\
\hline Wing shots & $5.9 \pm 1.5$ & $3.0-8.9$ & $5.2 \pm 1.3$ & $2.2-7.3$ \\
\hline Efficient wing shots & $3.2 \pm 1.1$ & $1.3-5.8$ & $3.2 \pm 1.1$ & $1.1-4.8$ \\
\hline
\end{tabular}

$\mathrm{n}=$ number of matches.

Statistically significant differences: ${ }^{*}=\mathrm{p}<0.05,{ }^{* *}=\mathrm{p}<0.01,{ }^{* * *}=\mathrm{p}<0.001$.

The analysis of overall efficiency and the efficiency of actions ending in shots for the World Championships in Qatar and Spain (Fig. 1) showed significantly higher overall efficiency $(+7.2 \%, \mathrm{p}<0.01)$ as well as higher efficiency of all shots $(+5.8 \%$, $\mathrm{p}<0.05)$, 6-m shots $(+9.5 \%)$, wing shots $(+7.3 \%)$, and breakthrough shots $(+11.4 \%)$. No significant differences were found in the efficiency of penalty $(7-m)$ throws or of free $(9-m)$ throws. 


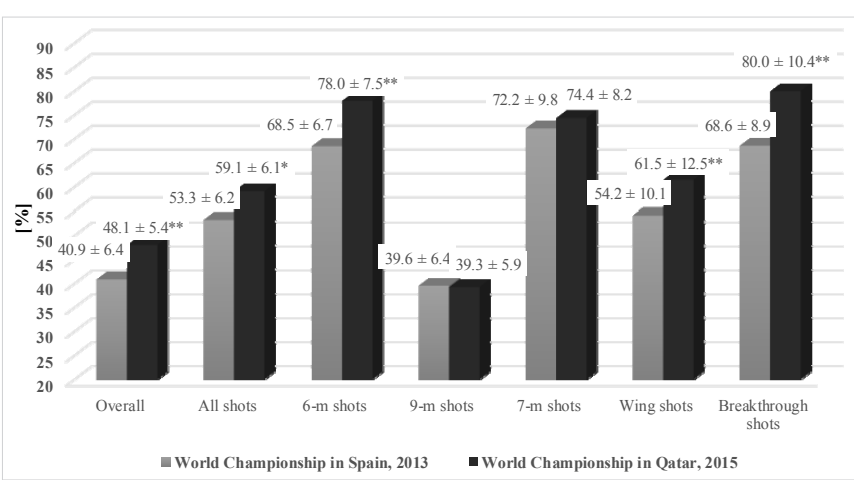

Statistically significant differences: ${ }^{*}=\mathrm{p}<0.05,{ }^{* *}=\mathrm{p}<0.001$.

Figure 1. Overall efficiency and efficiency of shots in positional attack during World Championships in Spain in 2013 and in Qatar in 2015

The analysis of the defensive actions taken by field defenders during the tournament in Qatar compared to that in Spain (Tab. 2) showed a significantly higher number of blocked shots $(+117.6 \%, \mathrm{p}<0.001)$ and 2 -minute suspensions $(+27.5 \%$, $\mathrm{p}<0.01$ ), with a simultaneous significant decrease in the number of steals $(-55.7 \%, \mathrm{p}<0.001)$ as well as that of saves made by goalkeepers $(-13.3 \%, \mathrm{p}<0.05)$.

As far as the efficiency of the goalkeepers' actions is concerned, there was a statistically insignificant reduction in the number of 9 -m shots defended $(-5 \%)$ and a significant decrease in the number of $6-\mathrm{m}$ shots $(-23.5 \%, \mathrm{p}<0.05)$, breakthrough shots $(-45.5 \%, \mathrm{p}<0.001)$ and wing shots $(-22.2 \%, \mathrm{p}<0.05)$ defended.

Further exploration of the results with regard to the quality of the game played by the goalkeepers during the World Championship in Qatar (Fig. 2) revealed a significant decrease in the efficiency of the defence with respect to $6-\mathrm{m}$ shots $(-4 \%$, $\mathrm{p}<0.05)$, breakthrough shots $(-8 \%, \mathrm{p}<0.001)$, and wing shots $(-5.5 \%, \mathrm{p}<0.05)$ compared to the tournament in Spain.

As for the differences between teams representing particular continents in terms of all of their technical-tactical actions (Tab. 3), it was found that during the World Championship in Qatar, there was a significant decrease $(\mathrm{p}<0.05)$ in the number of all actions for teams from Europe (-9.2\%), Asia (-5.7\%), and Africa (-4.8\%) compared to the championship in Spain. In both

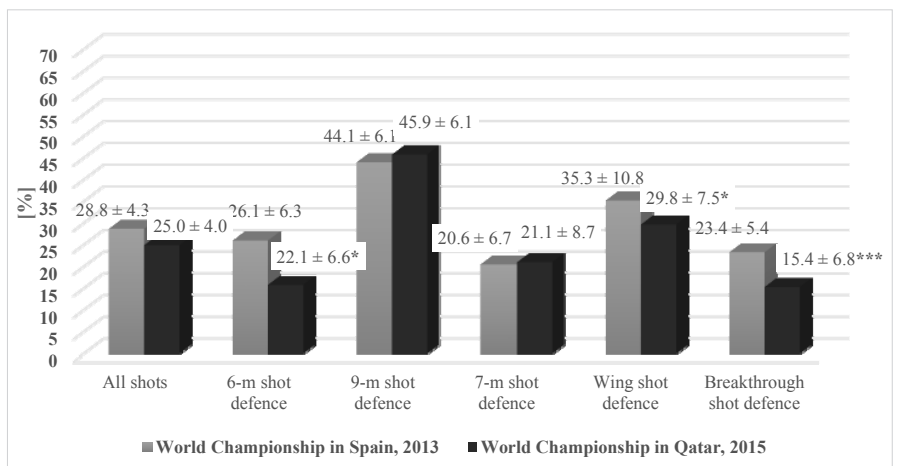

Statistically significant differences: ${ }^{*}=\mathrm{p}<0.05,{ }^{* *}=\mathrm{p}<0.01$.

Figure 2. Efficiency of goalkeeper defence during World Men's Handball Championships in Spain in 2013 and in Qatar in 2015 the tournament in Spain and in Qatar, European teams had a significantly higher number of efficient shots compared to teams from Asia (+10.4\% and $+11.3 \%$, respectively), Africa $(+13.1 \%$ and $+9.7 \%$, respectively), and America ( $+7.4 \%$ and $+7.1 \%$, respectively). When it comes to actions ending in 9-m shots (Tab. 3), there was a significantly lower number of 9-m shots in European teams compared to Asian teams in the championships in Spain $(-19.5 \%, \mathrm{p}<0.05)$ and Qatar $(-29.7 \%, \mathrm{p}<0.01)$. Asian teams had a higher $(+43.2 \%, \mathrm{p}<0.05)$ number of 9 -m shots with respect to teams from South America in the tournament in Qatar. As far as efficient wing shots are concerned, in the champion-

Table 2. Number of interventions of field defenders and goalkeepers during World Men's Handball Championships in Spain in 2013 and Qatar in 2015

\begin{tabular}{|l|c|c|c|c|}
\hline \multirow{2}{*}{\multicolumn{1}{c|}{ Variables }} & \multicolumn{2}{|c|}{$\begin{array}{c}\text { World Championship } \\
\text { in Spain, 2013 }(\mathbf{n = 8 4})\end{array}$} & \multicolumn{2}{c|}{$\begin{array}{c}\text { World Championship } \\
\text { in Qatar, 2015 (n= 88) }\end{array}$} \\
\cline { 2 - 5 } & $\bar{x} \pm$ SD & Min-Max & $\bar{x} \pm$ SD & Min-Max \\
\hline Steals & $9.7 \pm 4.4$ & $3.7-20.8$ & $4.3 \pm 0.8^{* * *}$ & $2.6-5.8$ \\
\hline Blocked shots & $1.7 \pm 1.4$ & $0.3-2.6$ & $3.6 \pm 1.2^{* * *}$ & $0.8-4.7$ \\
\hline Shots on goal & $39.2 \pm 4.2$ & $31.4-50.1$ & $39.2 \pm 2.8$ & $34.0-44.7$ \\
\hline Shots defended & $11.3 \pm 1.7$ & $8.1-16.1$ & $9.8 \pm 1.6^{*}$ & $7.1-14.3$ \\
\hline 6-m shots defended & $1.7 \pm 0.6$ & $0.8-3.1$ & $1.3 \pm 0.9^{*}$ & $1.0-3.1$ \\
\hline 9-m shots defended & $6.0 \pm 1.6$ & $2.4-9.7$ & $5.7 \pm 1.1$ & $3.7-7.8$ \\
\hline $\begin{array}{l}\text { Breakthrough shots } \\
\text { defended }\end{array}$ & $1.1 \pm 0.4$ & $0.4-1.8$ & $0.6 \pm 0.3^{* * *}$ & $0.1-1.3$ \\
\hline Wing shots defended & $1.8 \pm 0.5$ & $0.8-2.7$ & $1.4 \pm 0.4^{*}$ & $0.9-2.3$ \\
\hline 7-m shots defended & $0.7 \pm 0.3$ & $0.2-1.5$ & $0.8 \pm 0.4$ & $0.1-1.5$ \\
\hline 2-minute suspensions & $4.0 \pm 0.9$ & $2.1-5.7$ & $5.1 \pm 1.1^{* *}$ & $2.9-7.0$ \\
\hline
\end{tabular}

$\mathrm{n}=$ number of matches.

Statistically significant differences: ${ }^{*}=\mathrm{p}<0.05,{ }^{* *}=\mathrm{p}<0.01,{ }^{* * *}=\mathrm{p}<0.001$.

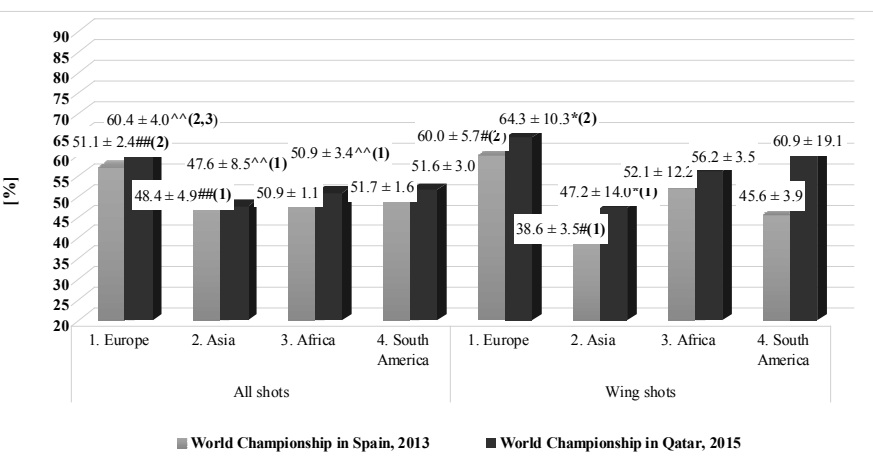

Statistically significant differences between World Championships in Spain and Qatar: ${ }^{*}=\mathrm{p}<0.05,{ }^{* *}=\mathrm{p}<0.01$, and ${ }^{* * *}=\mathrm{p}<0.001$; between continents during World Championship in Spain: ${ }^{\#}=\mathrm{p}<0.05,{ }^{\# \#}=\mathrm{p}<0.01$, \#\#\# $=\mathrm{p}<0.001$; and between continents during World Championship in Qatar: ${ }^{\wedge}=\mathrm{p}<0.05,{ }^{\wedge} \wedge=\mathrm{p}<0.01$, $\wedge \wedge \wedge=\mathrm{p}<0.001$.

Figure 3. Efficiency of shots during World Men's Handball Championships in Spain in 2013 and in Qatar in 2015 depending on continent represented 
ship in Qatar, European players performed better than Asian ones $(+111.7 \%, \mathrm{p}<0.05)$.

An analysis of defensive actions during the World Championship in Qatar compared to that in Spain (Tab. 3) revealed a significant decrease in the number of steals in teams from Europe $(-55.3 \%, \mathrm{p}<0.01)$, Asia $(-55.2 \%, \mathrm{p}<0.01)$, and Africa $(-66.1 \%, \mathrm{p}<0.001)$. Moreover, during both the tournament in Spain and in Qatar, European teams had a significantly higher $(\mathrm{p}<0.05)$ number of blocked shots compared to Asian and
South American teams $(+2.1$ per match and +1.70 per match, respectively).

When it comes to the efficiency of shots depending on the continent represented by the teams (Fig. 3), it was found that European teams had significantly higher shot efficiency $(+8.7 \%$, $\mathrm{p}<0.01)$ than Asian ones in the World Championship in 2013, whereas during the tournament in 2015, European teams had greater shot efficiency $(\mathrm{p}<0.01)$ not only with respect to Asian teams $(+12.8 \%)$ but also African ones $(+9.5 \%)$. The data for wing

Table 3. Number of offensive actions in positional attack during World Men's Handball Championships in Spain in 2013 and Qatar in 2015 depending on continent represented

\begin{tabular}{|c|c|c|c|c|c|}
\hline Variables & Tournament & $\begin{array}{c}\text { 1. Europe }(n=15) \\
\bar{x} \pm S D\end{array}$ & $\begin{array}{c}\text { 2. Asia }(n=3) \\
\bar{x} \pm S D\end{array}$ & $\begin{array}{l}\text { 3. Africa }(n=3) \\
\bar{x} \pm S D\end{array}$ & $\begin{array}{l}\text { 4. South America }(n=3) \\
\qquad \bar{x} \pm \text { SD }\end{array}$ \\
\hline \multirow{2}{*}{ All actions } & Spain 2013 & $52.3 \pm 2.3$ & $56.2 \pm 1.0$ & $52.1 \pm 2.7$ & $54.8 \pm 4.1$ \\
\hline & Qatar 2015 & $47.5 \pm 2.8^{*}$ & $53.0 \pm 3.9^{*}$ & $49.6 \pm 2.4^{*}$ & $53.6 \pm 4.4$ \\
\hline \multirow{2}{*}{ All shots } & Spain 2013 & $40.8 \pm 2.6$ & $43.6 \pm 2.1$ & $40.5 \pm 2.2$ & $42.0 \pm 2.7$ \\
\hline & Qatar 2015 & $37.4 \pm 2.3$ & $42.6 \pm 2.1$ & $40.5 \pm 1.8$ & $40.9 \pm 3.6$ \\
\hline \multirow{2}{*}{ Efficient shots } & Spain 2013 & $23.3 \pm 2.0^{\#}(2,3,4)$ & $21.1 \pm 3.2^{\#(1)}$ & $20.6 \pm 0.9 \#(1)$ & $21.7 \pm 1.1^{\#(1)}$ \\
\hline & Qatar 2015 & $22.6 \pm 1.9^{\wedge}(2,3,4)$ & $20.3 \pm 4.3^{\wedge}(1)$ & $20.6 \pm 1.2^{\wedge}(1)$ & $21.1 \pm 2.5^{\wedge}(1)$ \\
\hline \multirow{2}{*}{ Turnovers } & Spain 2013 & $11.5 \pm 1.4$ & $12.7 \pm 2.9$ & $11.6 \pm 1.5$ & $12.8 \pm 2.2$ \\
\hline & Qatar 2015 & $10.1 \pm 1.6$ & $10.4 \pm 2.9$ & $9.1 \pm 1.9$ & $12.7 \pm 1.8$ \\
\hline \multirow{2}{*}{ 9-m shots } & Spain 2013 & $18.1 \pm 2.3^{\#}(2)$ & $22.5 \pm 1.4^{\#}(1)$ & $19.7 \pm 2.1$ & $18.9 \pm 3.7$ \\
\hline & Qatar 2015 & $17.0 \pm 2.9^{\wedge \wedge}(2)$ & $24.2 \pm 2.5^{\wedge \wedge}(1)^{\wedge}(4)$ & $20.4 \pm 1.9$ & $16.9 \pm 1.7^{\wedge}(2)$ \\
\hline \multirow{2}{*}{ Efficient 9-m shots } & Spain 2013 & $7.8 \pm 1.2$ & $8.6 \pm 1.0$ & $7.2 \pm 2.3$ & $7.5 \pm 2.1$ \\
\hline & Qatar 2015 & $6.8 \pm 1.5$ & $7.8 \pm 1.8$ & $7.1 \pm 1.1$ & $5.4 \pm 0.6$ \\
\hline \multirow{2}{*}{ 6-m shots } & Spain 2013 & $7.2 \pm 2.1$ & $6.4 \pm 2.3$ & $7.7 \pm 1.4$ & $8.7 \pm 0.9$ \\
\hline & Qatar 2015 & $8.9 \pm 2.7$ & $8.9 \pm 3.2$ & $8.2 \pm 2.3$ & $10.4 \pm 1.9$ \\
\hline \multirow{2}{*}{ Efficient 6-m shots } & Spain 2013 & $5.0 \pm 1.6$ & $4.2 \pm 2.1$ & $5.3 \pm 0.8$ & $5.5 \pm 0.8$ \\
\hline & Qatar 2015 & $6.0 \pm 1.8$ & $5.6 \pm 2.5$ & $4.9 \pm 1.5$ & $6.0 \pm 0.9$ \\
\hline \multirow{2}{*}{ 7-m shots } & Spain 2013 & $3.7 \pm 1.1$ & $4.1 \pm 1.0$ & $2.8 \pm 0.3$ & $3.9 \pm 0.1$ \\
\hline & Qatar 2015 & $4.0 \pm 0.8$ & $3.4 \pm 0.4$ & $3.4 \pm 0.4$ & $4.2 \pm 1.0$ \\
\hline \multirow{2}{*}{ Efficient 7-m shots } & Spain 2013 & $2.9 \pm 1.0$ & $2.7 \pm 0.7$ & $2.1 \pm 0.5$ & $2.4 \pm 0.4$ \\
\hline & Qatar 2015 & $3.1 \pm 0.7$ & $2.3 \pm 0.6$ & $2.3 \pm 0.6$ & $3.0 \pm 0.5$ \\
\hline \multirow{2}{*}{ Breakthrough shots } & Spain 2013 & $5.3 \pm 1.3$ & $4.8 \pm 0.8$ & $5.4 \pm 3.4$ & $4.7 \pm 2.3$ \\
\hline & Qatar 2015 & $4.0 \pm 1.2$ & $3.5 \pm 1.1$ & $3.8 \pm 1.5$ & $4.8 \pm 0.0$ \\
\hline \multirow{2}{*}{$\begin{array}{l}\text { Efficient breakthrough } \\
\text { shots }\end{array}$} & Spain 2013 & $3.7 \pm 1.0$ & $3.4 \pm 0.7$ & $3.5 \pm 2.0$ & $3.7 \pm 1.4$ \\
\hline & Qatar 2015 & $3.1 \pm 1.1$ & $2.9 \pm 1.1$ & $3.0 \pm 1.1$ & $3.9 \pm 0.6$ \\
\hline \multirow{2}{*}{ Wing shots } & Spain 2013 & $6.5 \pm 1.4$ & $5.7 \pm 0.2$ & $4.8 \pm 1.6$ & $5.7 \pm 1.2$ \\
\hline & Qatar 2015 & $5.6 \pm 1.1$ & $3.6 \pm 1.3$ & $3.6 \pm 1.3$ & $4.6 \pm 1.4$ \\
\hline \multirow{2}{*}{ Efficient wing shots } & Spain 2013 & $3.9 \pm 0.9$ & $2.2 \pm 0.3$ & $2.5 \pm 1.0$ & $2.6 \pm 0.4$ \\
\hline & Qatar 2015 & $3.6 \pm 0.8^{\wedge}(2)$ & $1.7 \pm 0.7^{\wedge}(1)$ & $3.3 \pm 0.8$ & $2.8 \pm 1.6$ \\
\hline \multirow{2}{*}{ Blocked shots } & Spain 2013 & $3.2 \pm 1.3^{\#}(2,4)$ & $1.1 \pm 0.1 \#(1)$ & $1.4 \pm 0.2$ & $1.1 \pm 1.0 \#(1)$ \\
\hline & Qatar 2015 & $3.2 \pm 1.0^{\wedge}(2,4)$ & $1.5 \pm 0.8^{\wedge}(1)$ & $1.7 \pm 0.9$ & $1.5 \pm 0.4^{\wedge}(1)$ \\
\hline \multirow{2}{*}{ Steals } & Spain 2013 & $9.4 \pm 4.6$ & $9.6 \pm 2.2$ & $12.7 \pm 6.1$ & $6.6 \pm 1.1$ \\
\hline & Qatar 2015 & $4.2 \pm 0.9^{* *}$ & $4,3 \pm 0,0^{* *}$ & $4.3 \pm 0.8^{* * *}$ & $5.0 \pm 0.5$ \\
\hline 2-minute suspensions & Spain 2013 & $3.9 \pm 0.9$ & $4.0 \pm 0.9$ & $4.7 \pm 0.8$ & $3.8 \pm 0.2$ \\
\hline
\end{tabular}

$\mathrm{n}=$ number of teams.

Statistically significant differences between World Championships in Spain and Qatar: ${ }^{*}=\mathrm{p}<0.05,{ }^{* *}=\mathrm{p}<0.01,{ }^{* * *}=\mathrm{p}<0.001$; between continents during World Championship in Spain: ${ }^{\#}=\mathrm{p}<0.05,{ }^{\# \#}=\mathrm{p}<0.01,{ }^{\# \#}=\mathrm{p}<0.001$; and between continents during World Championship in Qatar: ${ }^{\wedge}=\mathrm{p}<0.05, \wedge \wedge=\mathrm{p}<0.01, \wedge \wedge \wedge=\mathrm{p}<0.001$. 
shots (Fig. 3) showed that European and Asian teams had higher $(\mathrm{p}<0.05)$ efficiency during the tournament in Qatar compared to that in Spain $(+4.3 \%$ and $+8.6 \%$, respectively). We also observed significantly higher $(+21.4 \%$, $\mathrm{p}<0.05)$ efficiency of wing shots for European players compared to Asian players during the World Championship in 2013. For the remaining types of shots, the efficiency of teams representing particular continents was similar.

\section{Discussion}

In analysing handball games, it is important to emphasise the predominance of actions carried out in positional attack, which constitute $75-85 \%$ of all actions performed during the game [5]. Therefore, considering the importance of this issue, in the current study, we focused on quantitative analysis and the analysis of the efficiency of offensive actions (in positional attack) and defensive actions recorded during the World Men's Handball Championships held in Spain in 2013 and in Qatar in 2015.

With regard to the decrease in the overall number of actions in positional attack (the number of 9-m shots and goals, breakthrough shots, and turnovers), it can be surmised that in this type of attack, players are forced to carry out long (group or team) actions in order to create the conditions for one of them to break through and make a shot. According to the results of the study, the time needed to organise an action in the so-called preparatory phase of a positional attack - during the entire match - has an impact on the quantitative characteristics of the elements used in the game, causing a decrease in the overall number of 9-m shots, breakthrough shots, and turnovers. Looking at similar studies by other others, the current study has also delivered evidence that modern handball players are most of all expected to cooperate with their teams and to finalise actions according to the tactical plan adopted [21, 25], which causes the time needed to prepare the action that is to lead to a shot to be longer and directly affects the end quantitative characteristics of the elements used in the game. The results recorded in the study can also be referred to the concept which emphasises, first and foremost, the accuracy of carrying out the action at the cost of the pace of its performance $[10,30]$.

Analysing the level of differences in the number and percentage of actions performed at particular distances from the goal in the World Championships in 2013 and 2015, we found a clear tendency in implementing the tactics of playing in positional attack that consisted in moving the place where the action was finalised to the region of the goal area line. This was evidenced by a significant increase in the number of 6-m shots with a simultaneous considerable decrease in the number of actions leading to 9-m shots.

Trying to identify the causes of the above phenomenon, one should also refer to the parameters describing the defensive actions and mention the increase in the number of shots blocked by the defenders in the playing area. This is undoubtedly related to the good individual preparation of these players, effective cooperation among field players in defending particular parts of the court, as well as the cooperation of field players with goalkeepers; players thus need to be successful in covering specific parts of the court and the goal. Analysing the changes in the characteristics of playing in positional attack in the context of the effectiveness of the performance of goalkeepers, one should also note the significant decrease in both the number of 6-m shots defended and the efficiency of defending 6-m shots, wing shots, and breakthrough shots.
Another factor which may have also affected the changes in the characteristics of the game in the two championships analysed are the parameters of defensive play, which showed a significant increase in the number of 2-minute suspensions during the World Championship in Qatar with respect to that in Spain. This can be seen as an effect of the increased activity and aggressiveness of the defence aimed at stealing the ball or interrupting the continuity of the actions being carried out by the opponent. The above fact is confirmed by the results of analyses performed by other authors with regard to the defensive play of field defenders [19, 31]; these authors have emphasised the importance of the high activity of the defence, thanks to which the opponent's actions are delayed and disrupted with tactical fouls.

Interpreting the differences in the features of the game depending on the continents the teams represented, we should emphasise that the findings of our study are in accordance with those of other authors [11, 21, 25, 29]. Due to implementing tactical plans consisting in attempting to finalise actions after team play and using efficient and aggressive defence, European teams attained an advantage in the number of goals after assists and blocked shots during the World Championships in Spain and Qatar. The involvement of players from Europe in the defence caused the opponents to make shots from beyond the 9-m line, and a smaller number of shots was carried out from back court positions in teams representing Europe.

Our belief that there is a need to perform systematic game analyses in handball is echoed in the works of Czerwiński [9] and Sevim and Bilge [29], who stress the fact that the results of such analyses make it possible to better understand the nature of the game in handball, where actions involving multiple players - each having good technical, tactical, and endurancerelated training as well as mental preparation - are key for successful performance in the game. This is also evidenced by the tendencies observed in handball over the course of the past few or several years.

\section{Conclusions}

The results of the study and the discussion have led us to formulate the following conclusions:

1. The tendencies observed in the game suggest that in their specific phase, training programmes should stress team actions which are to be finalised with a shot in the region of the opponent's goal area. This is particularly important with respect to national teams and elite teams.

2. The two-year cycle study revealed differences indicating developments in handball towards higher levels of activity and more aggressive play on the part of defensive players, as evidenced by the increase in the number of 2-minute suspensions found for the World Championship in Qatar.

3. The higher efficiency of individual and team actions in the attack as well as the efficient and aggressive defence implemented by European teams compared to those from Asia, Africa, and South America seems to indicate that the training system used in Europe is the most effective.

4. The increase in the number of blocked shots along with a decrease in the number of steals and effective goalkeeper interventions demonstrate that blocks are of increasing importance in handball, and these typically require field players to cooperate with each other as well as with the goalkeeper.

5. The analysis of the two-year cycle of the World Championships has revealed changes in the characteristics of offensive and defensive play, which should have an impact on specific 
training so that the highest level of sport performance can be achieved.

\section{Literature}

1. Jadach A., Ciepliński J. (2008). Level of physical preparation and its influence on selection of game concepts for the Polish national handball female team. Polish Journal of Sport and Tourism 15, 17-28.

2. Massuça L.M., Fragoso I., Teles J. (2014). Attributes of top elite team-handball players. Journal of Strength and Conditioning Research 28(1), 178-86. DOI: 10.1519/JSC.0b013e318295d50e.

3. Norkowski H. (2002). The intensity of effort in handball competitions in players in different positions during the game. Physical Education and Sport 46(2), 203-208. [in Polish]

4. Norkowski H., Śledziewski D., Perkowski K., Kuder A. (2014). The structure of effort intensity of handball players in different playing positions during game. Roczniki $\mathrm{Na}$ ukowe Wyższej Szkoły Wychowania Fizycznego i Turystyki w Biatymstoku 10, 108-112. [in Polish]

5. Czerwiński J. (2001). Characteristics of handball games based on the latest research. Człowiek i Ruch 3(1), 99-105. [in Polish]

6. Vukosavljević J., Kocić M., Berić D., Stojić M. (2015). The situation success in the handball: Review. Facta Universitatis Series: Physical Education and Sport 13(1), 97-105. UDC 797.012.

7. Zapartidis I., Toganidis T., Vareltzis I., Christodoulidis T., Kororos P., Skoufas D. (2009). Profile of young female handball players by playing position. Serbian Journal of Sports Sciences 3(1-4), 53-60. UDC: 796.322.012.1-055.2.

8. Balint E. (2012). An analysis of the performantial defense behavior of the top three male handball teams in comparison to the Romanian team in the World Championships, Sweden, 2011. Palestrica of the third millennium - Civilization and Sport 13(4), 333-338.

9. Czerwiński J. (2000). Statistical analysis and remarks on the game character based on the European Championship in Croatia. EHF Periodical 2, 5-11.

10. Gómez M., Lago-Peñas C., Viaño J., González-Garcia I. (2014). Effects of game location, team quality and final outcome on game-related statistics in professional handball close games. Kinesiology 46(2), 249-257. UDC: 796.322:796.092.298.

11. Bilge M. (2012). Game analysis of Olympic, World and European Championships in Men's Handball. Journal of $\mathrm{Hu}-$ man Kinetics 35, 109-118. DOI: 10.2478/v10078-012-00847.

12. Yamada E., Aida H., Fujimoto H., Nakagawa A. (2014). Comparison of game performance among European National Women's Handball Teams. International Journal of Sport and Health Science 12, 1-10. DOI: 10.5432/ijshs.201326.

13. Rudelsdorfer P., Schrapf N., Possegger H., Mauthner T., Bischof H., Tilp M. (2014). A novel method for the analysis of sequential actions in team handball. International Journal of Computer Science in Sport 13(1).

14. Ilić V., Macura M., Ranisavljev I. (2011). Profile of young elite handball players according to playing positions. RIK 39(1), 71-77. UDC: 796.322.085.

15. Michalsik L.B., Madsen K., Aagaard P. (2015). Technical match characteristics and influence of body anthropometry on playing performance in male elite team handball. Jour- nal Of Strength And Conditioning Research 29(2), 416-28. DOI: 10.1519/JSC.0000000000000595.

16. Lorger M., Prskalo I., Hraski M. (2013). Analyses of the efficiency game in attack and defence at young female handball players during the competition. Trakia Journal of Sciences 3, 314-317.

17. Santos F.M., Fernandez J., Oliveira M.C., Leitão C., Anguera T., Campaniço J. (2009). The pivot player in handball and patterns detection - Instrument. Motricidade 5(3), 29-36. DOI: 10.6063/motricidade.5(3).193.

18. Sporis G., Vuleta D., Vuleta Jr D., Milanovic D. (2010). Fitness profiling in handball: Physical and physiological characteristics of elite players. Collegium Antropologicum 34(3), 1009-1014.

19. Yiannakos A., Kougioumtzoglou A., Armatas V., Galazoulas C., Triantafillou P. (2007). Defense analysis of Greek Elite Handball Teams. Inquiries in Sport \& Physical Education 5(2), 308-314. [in Greek]

20. Bautista I.J., Chirosa I.J., Robinson J.E., Tillaar R., Chirosa L.J., Martin I.S. (2016). A new physical performance classification system for elite handball players: Cluster analysis. Journal of Human Kinetics 51(2), 131-142. DOI: 10.1515/ hukin-2015-0177.

21. Gruić I., Vuleta D., Milanović D. (2006). Performance indicators of teams at the 2003 Men's World Handball Championship in Portugal. Kinesiology 38(2), 164-175. UDC: 796. 322:796.056.2:796.092.1(469).

22. Gutiérrez O., Ruiz J.L. (2013). Game performance versus competitive performance in the World Championship of Handball 2011. Journal of Human Kinetics 36, 137-147.

23. Popovici I.M., Lupan L., Lupan V. (2013). The somatic, physical and technical model of the performance handball player, from the junior national team (17-18 years). Gymnasium Scientific Journal of Education, Sports, and Health 14(1), 5-20.

24. Schrapf N., Tilp M. (2013). Action sequence analysis in team handball. Journal of Human Sport and Exercise 8(3). DOI: 10.4100/jhse.2013.8.Proc3.07.

25. Gutiérrez O., Ruiz J.L. (2013). Data envelopment analysis and cross-efficiency evaluation in the management of sports teams: The assessment of game performance of players in the Spanish Handball League. Journal of Sport Management 27, 217-229.

26. Krawczyk P. (2015). Technical errors and the venue of the match in handball. Polish Journal of Sport and Tourism 22, 25-29. DOI: 10.1515/pjst-2015-0010.

27. Curițianu I., Neamțu M., Balint E. (2015). Analysis in attack of $6 \mathrm{~m}$ line players from male handball team Steaua Bucharest in Romanian National League. SPORT AND SOCIETY. Interdisciplinary Journal of Physical Education and Sports 15(Special Issue), 87-95.

28. Tudor V., Vărzaru C., Mujea A.M. (2015). Comparative study regarding the efficiency of handball players specialized on wing position from Danish and Romanian Championship. Gymnasium Scientific Journal of Education, Sports, and Health 16(1), 147-160.

29. Sevim Y., Bilge M. (2007). The comparison of the last Olympic, World and European Men Handball Championships and the current developments in world handball. Research Yearbook 13(1), 65-71.

30. Vuleta D., Milanović D., Sertić H. (2003). Relations among variables of shooting for a goal and outcomes of the 2000 Men's European Handball Championship matches. Kinesiology 35(2), 168-183. 
31. Calin R. (2015). The contribution of the goalkeepers of the France national team in winning the international handball competitions. Ovidius University Annals, Series Physical Education and Sport/Science, Movement and Health 15(1), 57-61.
32. Pori P., Šibila M., Justin I., Kajtna T., Pori M. (2012). Correlation between the motor abilities and competitive performance of Slovenian handball goalkeepers. Kinesiologia Slovenica 18(2), 19-26.

Submitted: May 10, 2017

Accepted: December 14, 2017 